Document downloaded from:

http://hdl.handle.net/10251/47737

This paper must be cited as:

Juárez Varón, D.; R. Balart; T. Boronat; Reig Pérez, MJ.; Ferrándiz Bou, S. (2013).

Validation of the Use of SEBS Blends as a Substitute for Liquid Silicone Rubber in Injection Processes. Materials and Manufacturing Processes. 28(11):1215-1221. doi:10.1080/10426914.2013.811732.

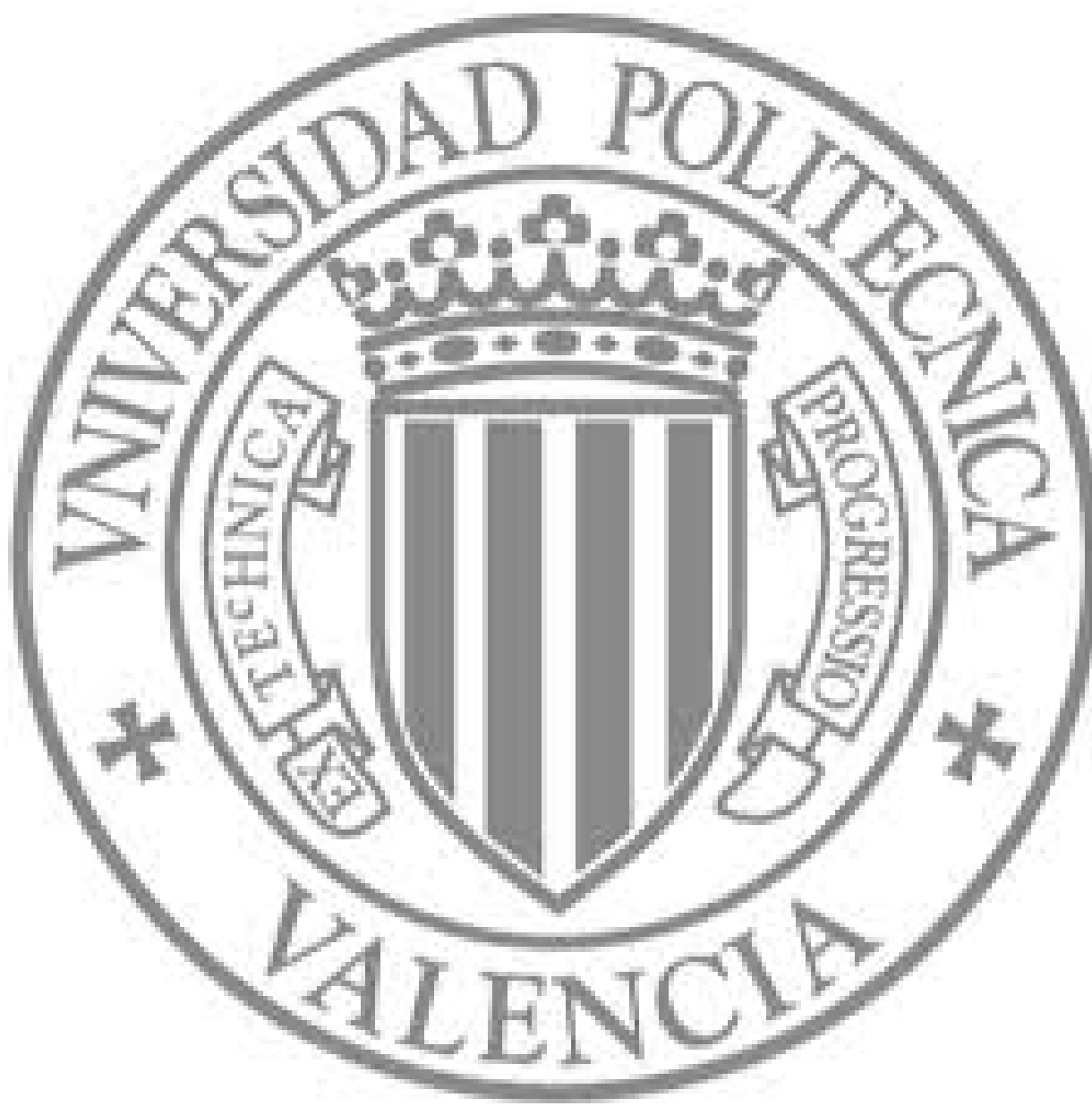

The final publication is available at

http://dx.doi.org/10.1080/10426914.2013.811732

Copyright Taylor \& Francis: STM, Behavioural Science and Public Health Titles 


\title{
Validation of the Use of SEBS Blends as a Substitute for Liquid Silicone Rubber in Injection Processes
}

\author{
D. Juarez, R. Balart, T. Boronat, M. J. Reig, and S. Ferrandiz \\ Universitat Politécnica de Valencia (UPV), Instituto de Tecnología de Materiales (ITM), Alcoy, \\ Spain
}

\begin{abstract}
Liquid silicone rubber is an interesting material at an industrial level, but there are great difficulties in the design and machining of molds, and in addition, it cannot be processed using conventional equipment. Therefore, new lines of research have focused on the search for new materials capable of providing final properties similar to liquid silicone rubber, that can also be engineered using simple, conventional processes and machinery. In this investigation, a range of compatible blends, based on two commercial grades of styrene-b-ethyleneco-butylene-bstyrene (SEBS) thermoplastic elastomer, was studied in order to obtain a range of different Shore A hardness blends for industrial applications where liquid silicone rubber (different hardness) is currently used. The two blended elastomers used had widely differing Shore A hardness values (5 and 90). Once the blended materials had been characterized, the Cross and Williams et al. [20] (Cross-WLF) mathematical model was applied in order to obtain theoretical performance curves for the viscosity of each of the blends. After this, a model was developed using the Computer Aided Engineering (CAE) software package Autodesk Moldflow 2012TM. This computer modeling validated the results obtained from the mathematical models, thus making available to process engineers the full range of hardnesses necessary for industrial products (where liquid silicone rubber is used), while still providing the advantages of thermoplastic injection molding.
\end{abstract}

Keywords Blend; CAE; Injection; Modeling; Rheology; SEBS; Silicone; Simulation

\section{INTRODUCTION}

In the last few years styrene polymers have received great attention due to the wide variety of properties that can be achieved with their use. Hydrogenation of styrenebutadiene-styrene rubber (SBS) leads to styrene-b-ethylene-co-butylene-b-styrene (SEBS) polymers. These are widely used as compatibilizers of other thermoplastics or as a blend to improve specific properties of a material (mainly impact resistance due the elastomeric nature of SEBS). 
It is possible to find different papers on the characterization of SEBS blends; Zhang et al. [1] investigated the mechanical performance of nylon 6 ternary composite blends with SEBS nano SiO2 particles, with controlled morphology. Feng-Hua et al. [2] analyzed the mechanical behavior of polypropylene-SEBS blends with organically modified montmorillonite (OMMT) and the effects of different formulations on the system's rheology.

Sugimoto et al. [3] analyzed the changes in morphology and rheology of SEBS blends combined with different hydrocarbons. There is very little literature about the use of SEBS as an individual material, but recently there has been increased interest in its use at the industrial level due to some of the properties that this material can provide, such as transparency and enhanced resistance to degradation by ultraviolet (UV) light and chemical attack. The detailed analysis of SEBS in terms of thermal and rheological characterization provides an efficient approach in order to solve problems in which there is some uncertainty about its behavior. There are various factors which have an influence on its behavior, and there is a range of variables that need to be studied.

Interesting new commercial grades of SEBS have been developed recently; these are characterized by high transparency, excellent chemical and light resistance, and easy processing. This has opened up the possibility of new applications by replacing other materials, such as liquid silicone, in some industrial processes for the manufacture of child care and orthopedics products, in which elastic properties, chemical inertness, and thermal stability are of great importance.

The research discussed in this article focuses on the use of two commercial SEBS grades (characterized by extreme Shore D hardness values, 5 and 90) to obtain SEBS materials with different mechanical properties [4-6] by the physical blending of these two extreme grades. The main aim of this study was to obtain a full range of material hardness while only using two references, thereby optimizing the material's processing and allowing SEBS to replace liquid silicone in industrial applications. The next step was to carry out rheological characterization of the blends by analyzing the changes in viscosity values at different temperatures for all the SEBS blends followed by subsequent mathematical modeling of the data obtained.

Using conventional Computer Aided Engineering (CAE) tools such as Autodesk Moldflow Inside 2012TM, the aim was to understand and analyze the injection process [7-11], using values obtained by fitting the Cross-WLF model to the experimental data. This gave key parameters to simulate the rheological behavior [12] of blends during the injection process. As these parameters are not included in the simulator for a given thermoplastic, it is necessary to determine them beforehand. 
Capillary rheometry is a useful technique for measuring changes in the viscosity of melted polymers in terms of temperature and shear rate. This technique is based on the extrusion of a melted polymer sample through a capillary of specific known dimensions and measuring the drop output pressure through the same nozzle at a known volumetric flow rate. After rheological characterization and modeling, different SEBS blends were injection molded in a standard mold for tensile tests, by using different parameters [13-17] determined by the theoretical model. Experimental results obtained from injected samples were then compared with the corresponding simulation obtained using the CAE tool Autodesk Molflow 2012TM.

\section{EXPERIMENTAL}

\section{Materials}

SEBS blends were made using two commercial grade transparent SEBSs characterized by extreme hardness values: Megol TA-51 and Megol TA-901 which were supplied by Applicazioni Plastiche Industriali (API). The generic properties of all SEBS Megol TA1 materials provided by the manufacturer are shown in Table 1. Blends used for the analysis of miscibility and subsequent rheological characterization are shown in Table 2.

\section{Processing of SEBS Blends}

SEBS blends of Megol TA-51 and Megol TA-901 were injected in a Mateu \& Sole'1 Meteor $270=75$ injection machine, using a standard tensile test sample mold.

A total of 15 samples per blend were injected for subsequent mechanical characterization. Injection conditions used for the selected injection temperature (180?] $)$ were recommended by the SEBS provider.

\section{Characterization of SEBS Blends}

The rheological characterization was analyzed using a capillary rheometer, ThermoHaake Rheoflixer MT1. Different temperatures (above and below the injection temperature recommended by the provider [18]) were used for rheological characterization (175]C and 185国).

The shear rates varied in the 100-10,000 1=s range. The rheometer tests were carried out in accordance with ISO 11443 . Three different nozzles ( $1 \mathrm{~mm}$ diameter) with length to diameter ratios of 10,20 , and 30 were used.

Once the apparent pressure curves were obtained, the shear stress and shear rate values were calculated by its conversion, using Bagley and Rabinowitsch corrections. 
The viscosity of the materials was then calculated from the ratio between Rabinowitsch and Bagley corrections, as shown in the following equation:

$\mu_{\text {corr }}=\frac{\tau_{c o r r}}{\gamma_{c o r r}}$

\section{Mathematical Modeling of the Theoretical Behavior of the Material's Viscosity}

The Cross [19] model was selected to determine the viscosity of the blended material because it is useful to simultaneously consider both the filling and the packing phases. The Cross approach is a powerful tool for accurately adjusting the temperature and pressure sensitivities in the case of zero shear-rate viscosity. A combination of the Cross approach along with the WLF expression ([20]) was used to calculate the viscosity of the material, with zero shear-rate processing conditions.

The Cross model expression is shown as in the following equation:

$$
\eta=\frac{\eta 0}{1+\left(\eta * \frac{r}{\tau}\right)(1-n)}
$$

where

$\boldsymbol{\eta}[\mathrm{Pa} \mathrm{s}]$ is the melt viscosity;

$\boldsymbol{\eta} 0[\mathrm{~Pa} \mathrm{~s}]$ is the viscosity value under zero shear-rate conditions;

$\tau[\mathrm{Pa}]$ the shear stress rate at the commencement of pseudoplastic behavior);

$r_{-}$is the shear rate (1=s); and

$\mathrm{n}[-]$ is the power law index in the high shear rate regime, representative of the pseudoplastic behavior in the form of a slope with value (1-n).

To calculate the viscosity values under zero shear-rate conditions, the WLF expression was selected, using the following equations:

$$
\begin{aligned}
& \eta_{0}= \begin{cases}\mathrm{D}_{1} \cdot \mathrm{e}^{\left(\frac{\left.-\mathrm{A}_{1}+\mathrm{T}-\tilde{\mathrm{T}}\right)}{\mathrm{A}_{2}+(\mathrm{T}-\mathrm{T})}\right),}, \text { if } \mathrm{T} \geq \widetilde{\mathbf{T}} \\
\infty, & \text { if } \mathrm{T}<\widetilde{\mathrm{T}}\end{cases} \\
& \mathrm{A}_{2}=\widetilde{\mathrm{A}}_{2}+\mathrm{D}_{3} \cdot \mathrm{p} \\
& \widetilde{\mathbf{T}}=\mathrm{D}_{2}+\mathrm{D}_{3} \cdot \mathrm{p},
\end{aligned}
$$


where

$\mathrm{D} 1[\mathrm{~Pa}$ s] is the viscosity value under zero shear-rate conditions at the glass transition temperature $(\mathrm{Tg})$ and atmospheric pressure;

A1 []ㅁ] shows the temperature dependence of Tg under zero shear-rate conditions;

$A 2[K]$ is a thermal parameter which depends on the material type;

$\mathrm{D} 3[\mathrm{~K}=\mathrm{Pa}]$ is directly related to the variation of the glass transition temperature $(\mathrm{Tg})$ in terms of pressure;

$\mathrm{T}[\mathrm{K}]$ represents the glass transition temperature $(\mathrm{Tg})$ and this values depends on the pressure;

$\mathrm{D} 2[\mathrm{~K}]$ represents the glass transition temperature $(\mathrm{Tg})$ at atmospheric pressure.

In accordance with this, the following values were adopted for the independent parameters of the SEBS blends used [21]:

$\mathrm{A} 2[\mathrm{~K}]=51,6 \mathrm{~K}$

$\mathrm{D} 2=\mathrm{Tm}=100 \circ \mathrm{C}=373,5$ ㅇ $\mathrm{K}$

D3 $=\delta \mathrm{Tg} / \delta \mathrm{p} \approx \mathrm{i} 0 \mathrm{~K} / \mathrm{Pa}$

\section{RESULTS AND DISCUSSION}

Characterization of the SEBS Blendsrheology

Rheological characterization of the family of blends was carried out at two temperatures, 175 ? $\mathrm{C}$ and 185 国.

Figure 1 shows the experimental results for the rheological characterization of the different blends, ranging from 100 wt\% SEBS with hardness 90, to 100 wt\% SEBS with hardness 5 . The curves show the change in viscosity vs. shear rate for all the blends studied. Blend number 1 is $100 \%$ Megol TA-901 SEBS, which is the hardest material.

The results show decreasing viscosity values with increasing weight percentage of the other material studied (Megol SEBS TA-51). All the curves clearly show a marked pseudoplastic behavior as the shear rate has a negative effect on viscosity.

The values obtained suggest a normal behavior with regard to viscosity changes. Initially, a graphical representation of viscosity at 175]C and 185]C was produced using experimentally obtained data, for the sample M05 (70 30) (Fig. 2). This sample can be considered as an ideal alternative to other types of materials currently in use (liquid silicone rubber). 


\section{Comparison of Experimental Data with the Theoretical Model}

The most important parameters determined from mathematically modeling the blends according to the Cross model are shown in Table 3. The following are some comparative values for both the experimental data and theoretical values obtained with the Cross model.

The first comparison was made for sample M03 $(3070)$ at 175? C, Figure 3(a). The graph shows that the mathematical model is optimally adjusted to the experimental data.

For shear rates at or above $10,000 \mathrm{~s}$ ? 1 it can be seen that the experimental data provides viscosity values that are lower than the mathematical model. For values above $700 \mathrm{~s}$ ? 1 the viscosity of the theoretical model is somewhat closer to the experimental viscosity data.

The same operation was performed for sample M04 (50 50) at 175]C, Fig. 3(b). The theoretical model yielded viscosity values a little higher than the viscosity obtained experimentally.

The next sample studied was M05 (70 30) at 175] C, Fig. 3(c). When shear rates are over 10,000 $s$ ?1, small differences appeared between viscosities, with lower viscosity values obtained from the experimental data. For shear rates below $1000 \mathrm{~s}$ ? 1 , the theoretical and experimental viscosity values were in accordance.

\section{Mathematical Modeling of $\boldsymbol{n}$ Values}

The next step was to study the modeling of the value of the $\mathrm{n}$ factor. This factor is a part of the Cross expression, expressed as 1-n. It represents the change in pseudoplastic behavior which can be interpreted as an indicator of the influence of shear rate on viscosity in the pseudoplastic zone. This parameter can only vary in the range $0-1$. If $n \frac{1}{1} 1$, the polymer behaves like a Newtonian fluid. In contrast, if $n 1 / 40$ the polymer will behave like a pure pseudoplastic. The $n$ values shown in Table 4 indicate that $\mathrm{n}$ tends to increase as the weight percentage of the soft SEBS (hardness 5) increases. This means that there is an exponential variation in $n$ values demonstrating that the viscosity will decrease as $n$ increases. The first sample (0\% SEBS Megol TA-51- 100\% SEBS Megol TA-901) had an $n$ value of 0.35 , which can be correlated with the highest viscosity of this material.

The other values indicate an upward trend that should be interpreted as a decrease in viscosity due to the presence of higher amounts of low viscosity SEBS (hardness 5). The remaining samples tend to have Newtonian behavior values. A maximum $n$ value was recorded in the last blend (100\% SEBS Megol TA-51-0\% SEBS Megol TA-901) which corresponds to the least viscous material used As far as manufacturing is concerned, it is important that a polymer has pseudoplastic behavior, this means low $\mathrm{n}$ values and therefore high slopes, which in turn means lower viscosity values for the same shear rate. 
Table 4 shows the results obtained for $s$ values. This value indicates the shear stress, which determines the starting point of pseudoplastic behavior. The change of the value obtained shows an undulating variation effect due to the rebound in values for samples M02 and M06. The conclusion shown in Table 4 is a trend to zero, as the percentage of SEBS Megol TA-901 increased in the blend. The conclusion that can be drawn is that it overrides the pseudoplastic transition zone in the material as the percentage of the hardest SEBS increased.

There was also a trend to zero in D1 values, see Table 3. The D1 parameter indicates the polymer's viscosity, under null shear conditions, at the glass transition temperature ( $\mathrm{Tg})$, and under atmospheric pressure. The injection process industry is continually trying to increase processability in the injection process and this can be achieved by lowering viscosity (D1) to facilitate the flow of material in the compaction phase.

In this case, the $\mathrm{A} 1$ values increased as the M07 sample values were approached. The constant A1 quantifies the variation of viscosity as a function of temperature.

\section{Simulation of the Injection Molding Process}

Finally, experimental validation of the modeled data was carried out using injection equipment. For thisvalidation, the values of the variables calculated in previous sections for blends of $70 \%$ SEBS Megol TA-51-30\% SEBS Megol TA-901 were tested.

Different filling tests were carried out by maintaining a constant injection time and decreasing the injection rate gradually until there is no flow of material into the mold cavity. This is equivalent to modifying the injection pressure.

Parallel to the filling machine tests, simulations of the process were also carried out using the modelingprogram Autodesk Moldflow 2012TM. This allowed comparisons to be made between the progress of the experimental data and the theoretical flow.

The experimental validation involved filling different samples at different injection rates. The injection machine used sets the injection rates in percent, while the compaction pressure was kept constant at values close to zero. The injection time was kept constant as well.

The next step was programming the equivalent experimental values in Autodesk Moldflow 2012TM. The same values of time and compaction pressures were entered along with the same values of injection time with programmed injection speed values.

The first sample verified, Fig. 4(a), showed a percentage of actual filling of $59.8 \%$ at a filling rate of $10.6 \mathrm{~cm} 3=\mathrm{s}(10 \%$ injection rate). This figure of $10.6 \mathrm{~cm} 3=\mathrm{s}$ was introduced into the simulator, and the simulation was run. The results were very similar $(60.3 \%)$ to the experimental values obtained under the same processing conditions. A deviation of $0.8 \%$ was obtained between simulated and experimental data. 
The same methodology was applied for an injection rate of 12\%, Fig. 4(b). The model predicted a filling of $86 \%$. Just as in the previous case, the speed of the simulator was programmed with a value of $12.7 \mathrm{~cm} 3=\mathrm{s}$. Figure $4(\mathrm{~b})$ shows the comparative values obtained for the experimental and theoretical test pieces. The modeled filling rate was $86 \%$, compared to the actual rate of $85.3 \%$ for the experimental test. The deviation was $0.7 \%$ between the simulated model and the real injection molding process.

\section{CONCLUSIONS}

Rheological characterization of a series of SEBS Megol TA-51 and SEBS Megol TA-901 blends in different proportions was carried out at temperatures of 175]C and 185]C. Once the viscosity curves were established experimentally, the dependent variables in the mathematical model were determined, and then the viscosity curve was established according to a mathematical model. The observed correlation between the experimental model and mathematical model was found to be satisfactory, despite featuring a small deviation at shear speeds exceeding 10,000 s? 1.

Following this, a study of the change in $\mathrm{n}$ factor and associated dependent variables was carried out in order to analyze the trend of values. These values show an upward trend, demonstrating a decreasing variation in viscosity as viscosity decreases. Finally, we injected the set of blends into a standard mold for samples designed for tensile tests, comparing the results with those provided by the mathematical model and its simulation by the CAE Autodesk Molflow 2012TM tool. The experimental validation of calculated mathematical model predictions showed a good alignment between the mathematical model and the experimental data.

This research validates the results obtained from the mathematical models that simulate the behavior ofnew blends of SEBS made solely from two reference materials, thus allowing the production of an injection molding material which exhibits the full range of hardness values available in liquid silicone rubber and necessary for the manufacture of industrial products (where liquid silicone rubber is currently used), while retaining the advantages of thermoplastic injection processing. Finally, this research demonstrates the potential for formulating any combination of two references from a recyclable thermoplastic material, recently incorporated into the market, in order to substitute for injected liquid silicone (a thermoset material that is nonrecyclable and difficult to process) in the main industrial applications (including biocompatibility), thus simplifying processing and drastically reducing the need to store raw materials. 


\section{ACKNOWLEDGMENTS}

The authors wish to thank "Ministerio de Ciencia e Innovación" IPT-310000-2010-37 and Universidad Politecnica de Valencia PAID 10012 for their financial support.

\section{REFERENCES}

1. Zhang, B.Q.; Wong, J.S.P.; Shi, D.; Yam, R.C.M.; Li, R.K.Y. Investigation on the mechanical performances of ternary Nylon 6=SEBS elastomer=nano-SiO2 hybrid composites with controlled morphology. Journal of Applied Polymer Science 2010, 115 (1), 469-479.

2. Su, F.H.; Huang, H.X. Mechanical and rheological properties of $P P=S E B S=O M M T$ ternary composites. Journal of Applied Polymer Science 2009, 112 (5), 3016-3023.

3. Sugimoto, M.; Sakai, K.; Aoki, Y.; Taniguchi, T.; Koyama, K.; Ueda, T. Rheology and morphology change with temperature of SEBS=hydrocarbon oil blends. Journal of Polymer Science Part BPolymer Physics 2009, 47 (10), 955-965.

4. Jose, A.J.; Alagar, M.; Thomas, S.P. Preparation and characterization of organoclay filled polysulfone nanocomposites. Materials and Manufacturing Processes 2012, 27 (3), 247-254.

5. Ivanovic, N.; Marjanovic, N.; Novakovic, J.G.; Manasijevic, M.; Rakocevic, Z.; Andric, V.; Hadzic, B. Experimental and theoretical investigations of cured and uncured disiloxane bisbenzocyclobutene thin films. Materials and Manufacturing Processes 2009, 24 (10-11), 1180-1184.

6. Perisic, M.; Radojevic, V.; Uskokovic, P.S.; Stojanovic, D.; Jokic, B.; Aleksic, R. Woodthermoplastic composites based on industrial waste and virgin high-density polyethylene (HDPE). Materials and Manufacturing Processes 2009, 24 (10-11), 1207-1213.

7. Iqbal, H.; Sheikh, A.K.; Al-Yousef, A.; Younas, M. Mold design optimization for sand casting of complex geometries using advance simulation tools. Materials and Manufacturing Processes 2012, 27 (7), 775-785.

8. Ozek, C.; Celik, Y.H. Calculating molding parameters in plastic injection molds with ANN and developing software. Materials and Manufacturing Processes 2012, 27 (2), 160-168.

9. Hirschmanner, M.; Moerwald, K.; Froehlich, C. Next generation mold level control: development of LevCon 2.0. Materials and Manufacturing Processes 2011, 26 (1), 169-174.

10. Selvakumar, P.; Bhatnagar, N. Studies on polypropylene= carbon fiber composite foams by nozzle-based microcellular injection molding system. Materials and Manufacturing Processes 2009, 24 (5), 533-540.

11. Gramegna, N.; Della Corte, E.; Poles, S. Manufacturing process simulation for product design chain optimization. Materials and Manufacturing Processes 2011, 26 (3), 527-533. 
12. Markovic, G.; Radovanovic, B.; Marinovic-Cincovic, M.; Budinski-Simendic, J. The effect of accelerators on curing characteristics and properties of natural rubber= chlorosulphonated polyethylene rubber blend. Materials and Manufacturing Processes 2009, 24 (10-11), 12241228.

13. Mehat, N.M.; Kamaruddin, S. Investigating the effects of injection molding parameters on the mechanical properties of recycled plastic parts using the Taguchi method. Materials and Manufacturing Processes 2011, 26 (2), 202-209.

14. Chen, C.-C.; Su, P.L.; Chiou, C.B.; Chiang, K.T. Experimental investigation of designed parameters on dimension shrinkage of injection molded thin-wall part by integrated response surface methodology and genetic algorithm: A case study. Materials and Manufacturing Processes 2011, 26 (3), 534-540.

15. Martinez, A.; Castany, J.; Aisa, J. Characterization of in-mold decoration process and influence of the fabric characteristics in this process. Materials and Manufacturing Processes 2011, 26 (9), 1164-1172.

16. Benitez-Rangel, J.P.; Trejo-Hernandez, M.;Morales-Hernandez, L.A.; Dominguez-Gonzalez, A. Improvement of the injection mold process by using vibration through a mold accessory. Materials and Manufacturing Processes 2010, 25 (7), 577-580.

17. Chen, C.C. Design of Effective parameters on the wickdebinding process for powder injection molded green compact. Materials andManufacturing Processes 2011, 26 (10), 1261-1268.

18. Boronat, T.; Segui, V.J.; Peydro, M.A.; Reig, M.J. Influence of temperature and shear rate on the rheology and processability of reprocessed ABS in injection molding process. Journal of Materials Processing Technology 2009, 209 (5), 2735-2745.

19. Cross, M.M. Rheology of non-Newtonian fluids: A new flow equation for pseudoplastic systems. Journal of Colloid Science 1965, 20 (5), 417-437.

20. Williams, M.L.; Landel, R.F., Ferry, J.D. Temperature dependence of relaxation mechanisms in amorphous polymers and other glass-forming liquids. Physical Review 1955, 98 (5), 15491549.

21. Reig, M.J.; Segui, V.J.; Zamanillo, J.D. Rheological behavior modeling of recycled ABS=PC blends applied to injection molding process. Journal of Polymer Engineering 2005, 25 (5), 435-457. 


\section{FIGURE CAPTION}

TABLE 1.-Characteristics of a series of commercial grade Megol TA ${ }^{\circledR}$ of poly styrene-b-ethylene-co-butylene-b-styrene (SEBS).

\begin{tabular}{ll} 
Shore hardness range & $5-90 \mathrm{~A}$ \\
Compatibility & $\begin{array}{c}\text { PP-PE- } \\
\text { EVA }\end{array}$ \\
Ageing resistance Ozone $\left(72 \mathrm{~h}-40^{\circ} \mathrm{C}-200 \mathrm{ppcm}\right)$ & Excellent \\
$\quad$ Tension $=20 \%$ & \\
Weathering & Excellent \\
Density $\left(\mathrm{g} / \mathrm{cm}^{3}\right)$ & $0.88-0.89$ \\
Tear strength w.n. $(\mathrm{kN} / \mathrm{m})$ & $22-44$ \\
Tensile modulus $100 \%$ elongation $(\mathrm{MPa})$ & $1.1-4.2$ \\
Tensile modulus $300 \%$ elongation $(\mathrm{MPa})$ & $1.9-5$ \\
Tensile strength $(\mathrm{MPa})$ & $6-7.2$ \\
Elongation at break $(\%)$ & $700-550$ \\
\hline
\end{tabular}

TABLE 2.-Blend composition (weight percentage) of SEBS Megol TA $-5^{{ }^{\mathbb{R}}}$ and Megol TA- $90^{\circledR}$ for rheological characterization.

\begin{tabular}{lcc}
\hline & SEBS MEGOL TA-5 & SEBS MEGOL TA-90 \\
\hline BLEND 1 & $0 \%$ & $100 \%$ \\
BLEND 2 & $10 \%$ & $90 \%$ \\
BLEND 3 & $30 \%$ & $70 \%$ \\
BLEND 4 & $50 \%$ & $50 \%$ \\
BLEND 5 & $70 \%$ & $30 \%$ \\
BLEND 6 & $90 \%$ & $10 \%$ \\
BLEND 7 & $100 \%$ & $0 \%$ \\
\hline
\end{tabular}
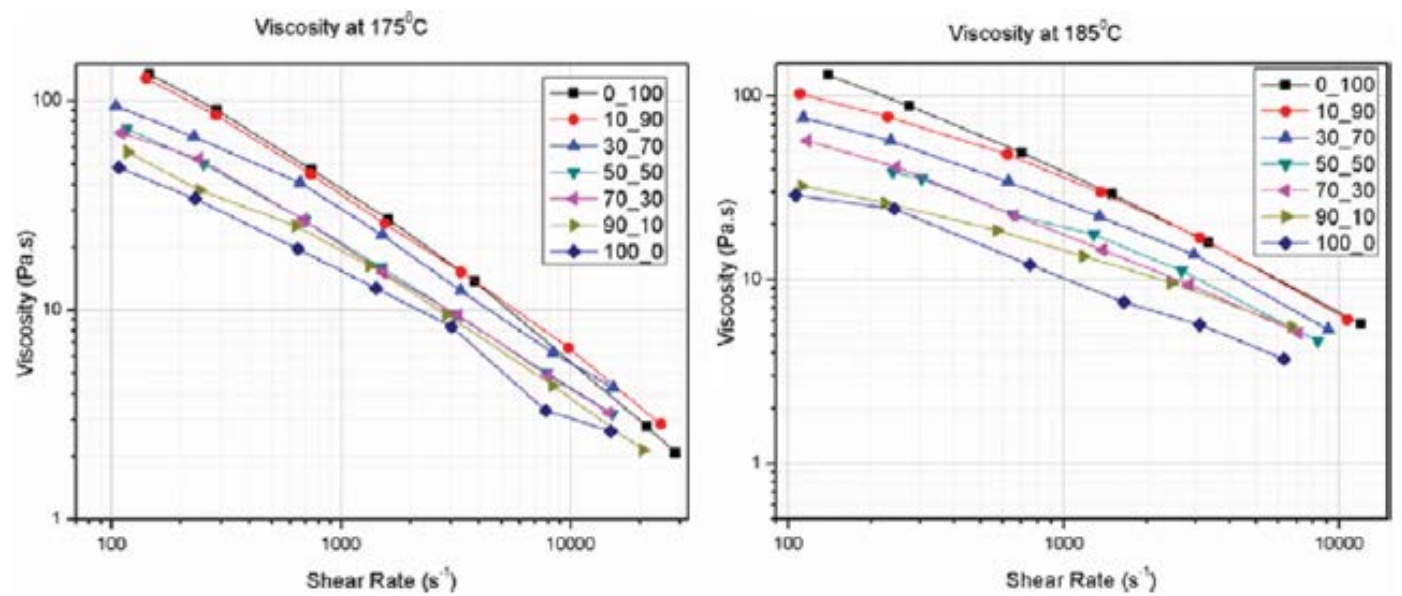

Figure 1.-Variation of the viscosity for different SEBS blends in terms of the shear rate at $175^{\circ} \mathrm{C}$ and $185^{\circ} \mathrm{C}$ (color figure available online). 
30_70 Mix Sample

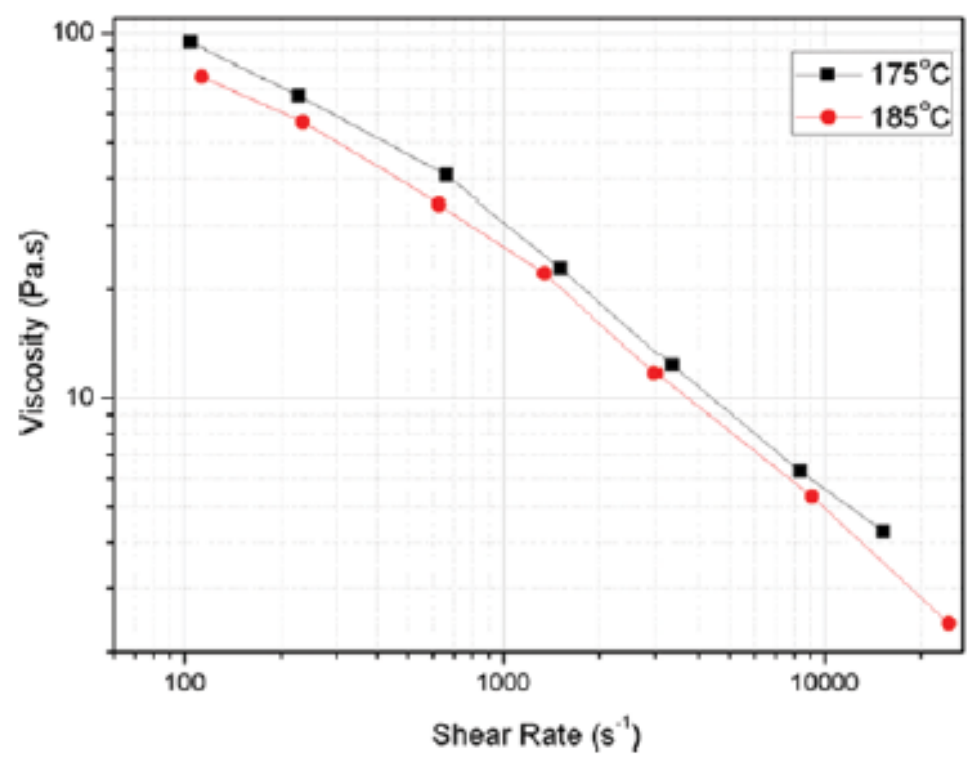

Figure 2.-Comparison of the viscosity curves for the 30-70 blend in terms of the shear rate (color figure available online).

TABLE 3.-Dependent Cross-WLF parameters of SEBS Megol TA- $5^{60}$ and SEBS Megol TA- $90^{60}$ blends.

\begin{tabular}{llcccc}
\hline Material & \multicolumn{1}{c}{$\mathrm{D}_{1}[\mathrm{~Pa}]$} & $\mathrm{A}_{1}[-]$ & $\tau[\mathrm{Pa}]$ & $\mathrm{n}[-]$ & $\eta_{\mathrm{o}}\left[175^{\circ} \mathrm{C} / 185^{\circ} \mathrm{C}\right][\mathrm{Pas}]$ \\
\hline M01: SEBS5_90_0-100 & $5.28 \mathrm{E}+12$ & 4.57481 & 0.14328 & 0.35319 & $2.10 \mathrm{e}+12 / 1.28 \mathrm{e}+12$ \\
M02: SEBS590_10-90 & $6.29443 \mathrm{E}+12$ & 11.91098 & 0.13632 & 0.40141 & $5.72 \mathrm{e}+11 / 1.6 \mathrm{e}+11$ \\
M03: SEBS5_90_30-70 & $2.49858 \mathrm{E}+11$ & 11.81668 & 0.21189 & 0.42954 & $2.32 \mathrm{e}+10 / 6.5 \mathrm{e}+9$ \\
M04: SEBS590_50-50 & $2.96452 \mathrm{E}+11$ & 8.58608 & 0.07274 & 0.40750 & $5.27 \mathrm{e}+10 / 2.1 \mathrm{e}+10$ \\
M05: SEBS5990_70-30 & $9.52 \mathrm{E}+12$ & 14.77000 & 0.01220 & 0.44338 & $1.52 \mathrm{e}+09 / 9.77 \mathrm{e}+08$ \\
M06: SEBS5_90_90-10 & $3.30 \mathrm{E}+12$ & 14.10000 & 0.02100 & 0.46013 & $7.78 \mathrm{e}+08 / 5.11 \mathrm{e}+08$ \\
M07: SEBS5_90_100-0 & $1.3956 \mathrm{E}+11$ & 15.80911 & 0.05090 & 0.48895 & $5.8 \mathrm{e}+9 / 1.06 \mathrm{e}+9$ \\
\hline
\end{tabular}




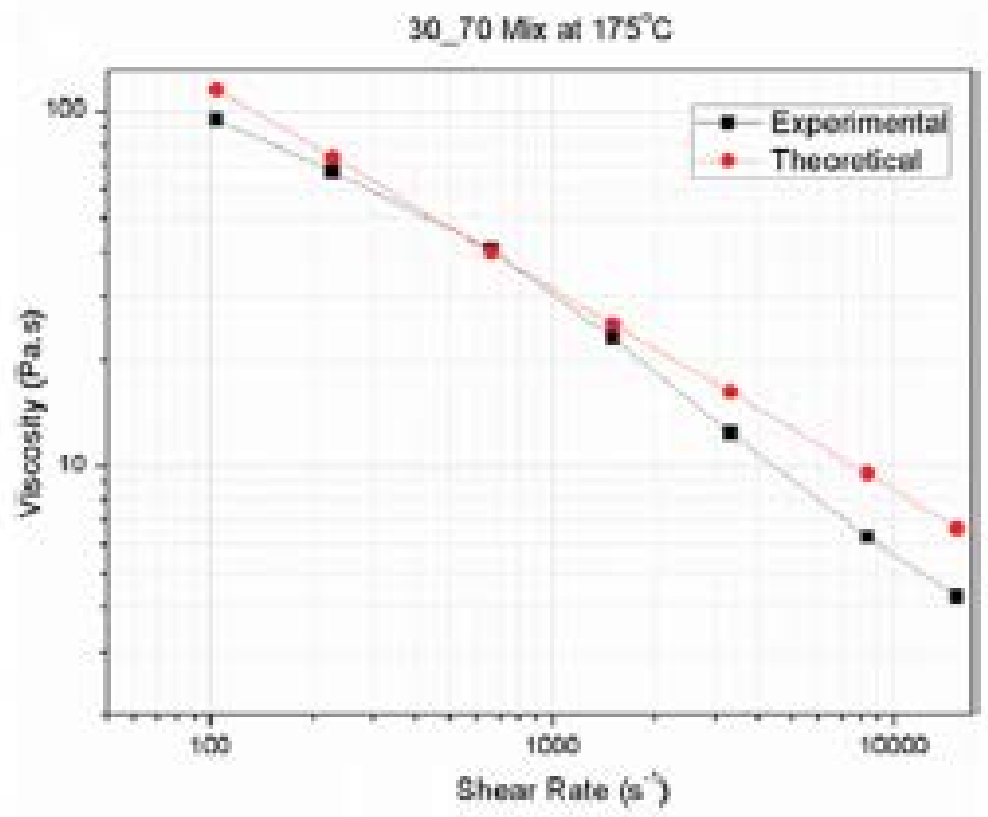

(a)

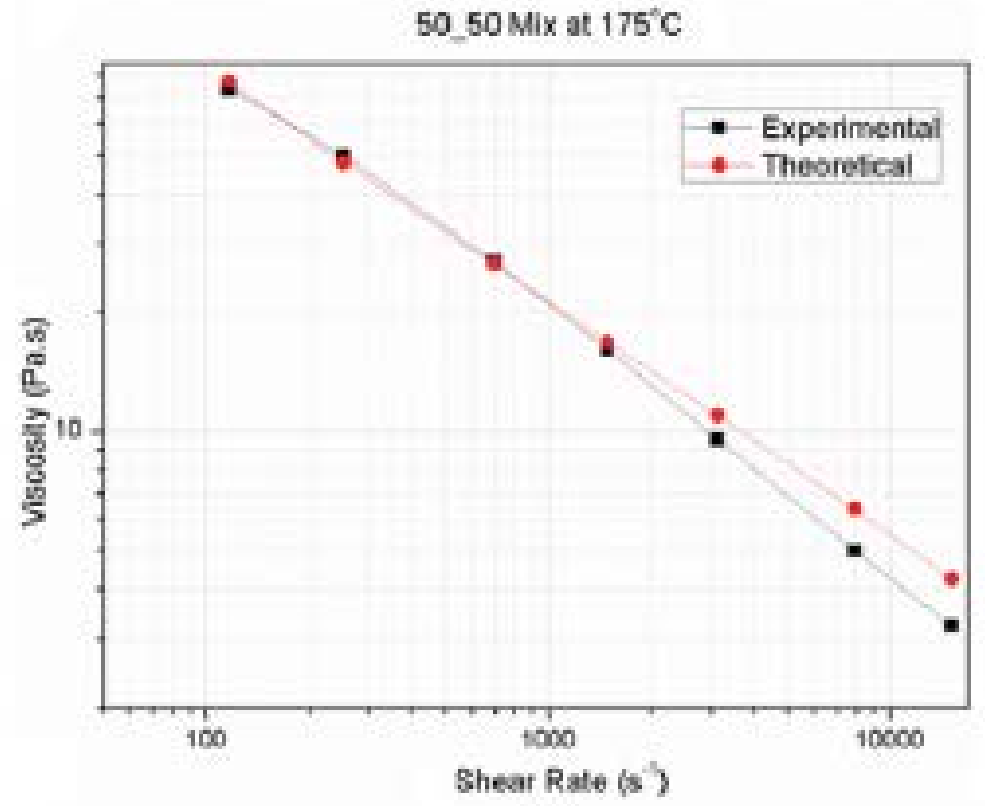

(b)

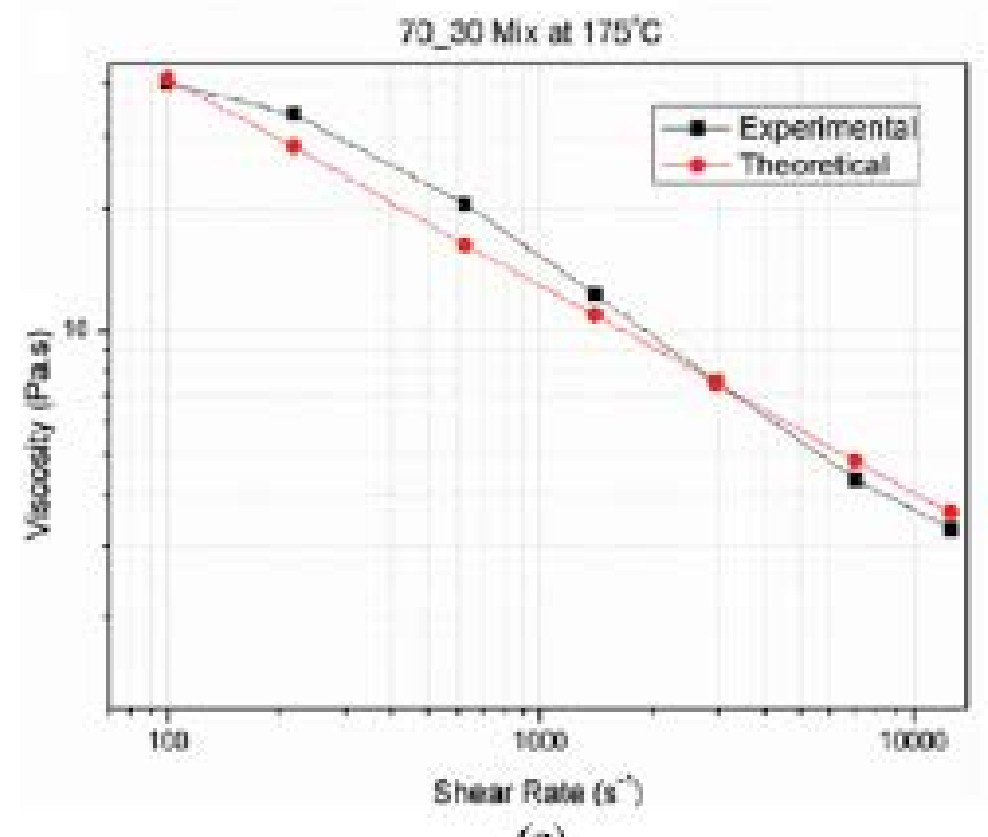


TARi.E 4. $-\tau$ and $n$ val ues of SEBS Megol TA $-5^{k}$ and SEBS Megol TA- $90^{R}$ blends.

\begin{tabular}{lcc}
\hline Material & $\tau\left[\mathrm{P}_{2}\right]$ & $\mathrm{n}[-]$ \\
\hline M01: SEBSS90_0-100 & 0.14328 & 0.35319 \\
M02: SEBSS_90_10-90 & 0.13632 & 0.40141 \\
M03: SEBS590_30-70 & 0.21189 & 0.42954 \\
M04: SEBS590_S0-S0 & 0.07274 & 0.40750 \\
M0S: SEBS590_70-30 & 0.01216 & 0.44338 \\
M06: SEBS590_90-10 & 0.02100 & 0.46013 \\
M07: SEBS590_100-0 & 0.05090 & 0.48895 \\
\hline
\end{tabular}
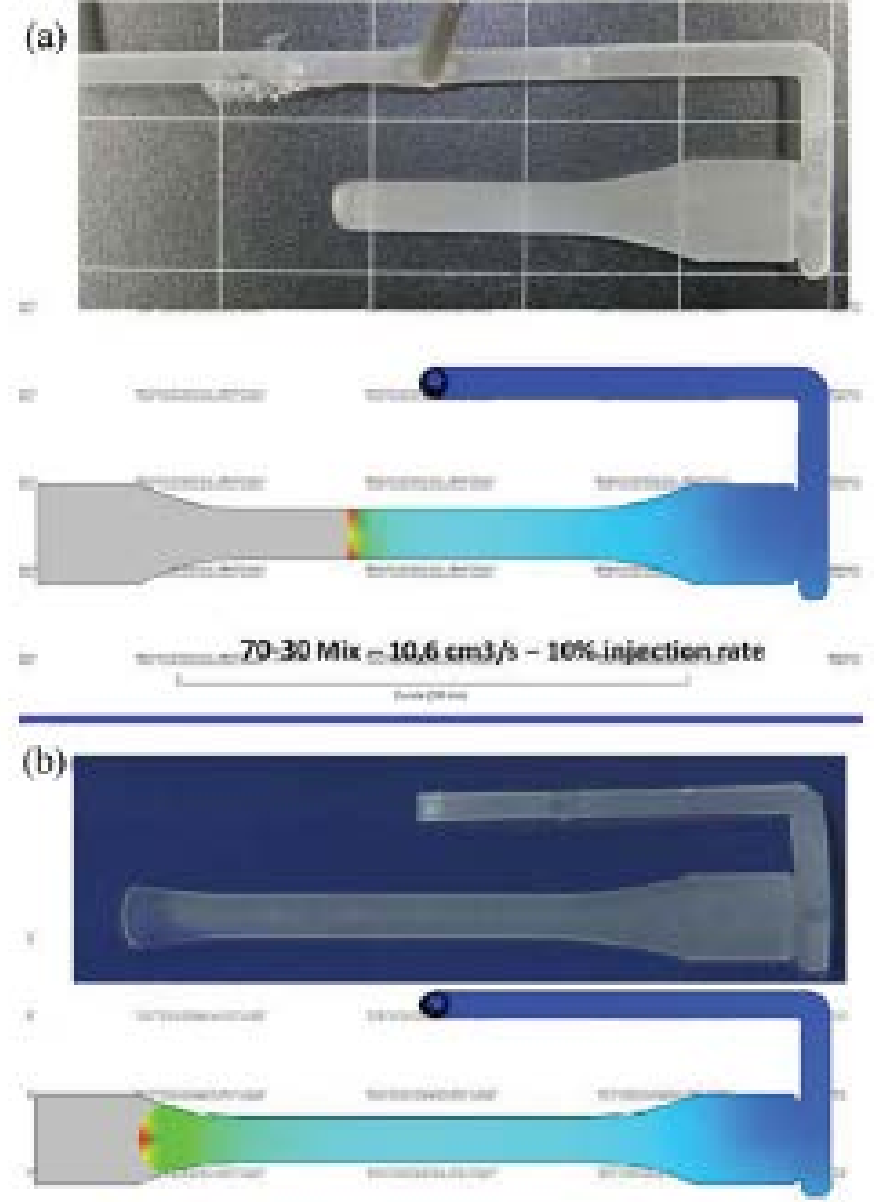

- 70-90 Mix $-12,7 \operatorname{cr} 3 /, 0,12 \times$ injection rate

Ficure 4. Comparison of test data and simulation for injected samples with a $0 \%$ SEBS Megol TA-5 $5^{\mathbb{R}}-100 \%$ SEBS Megol TA- $90^{\mathbb{R}}$ blend (a) and $70 \%$ SEBS Megol TA $-5^{R}-30 \%$ SEBS Megol TA $-30^{R}$ blend (b) (color figure avalable online). 
